\title{
Annual Meeting minutes of the Chinese Geoscience Union, 2020
}

\author{
Chinese Geoscience Union Annual Meeting Organizing Committee
}

\begin{abstract}
The Seventh Annual Meeting of the Chinese Geoscience Union was held in Chongqing Yuelai International Convention Center, from October 18 to 212020 , together with the $36^{\text {th }}$ Annual Meeting of Chinese Geophysical Society which was held. This annual meeting convened one main venue and 31 academic conference venues, hosting 92 sessions with 51 of them focused on geophysics (including one English session). In addition, there were also six union-wide invited talks, 5 presentations on the frontiers of geophysics, and 8 award lectures for the 2020 Fu Chengyi Young Scientist Awardees. The annual meeting received about $3200 \mathrm{ab}-$ stracts, 2150 of which were oral presentations and 950 as posters. In total, there were about 4000 participants from the scientific community and more than 80 exhibitors.
\end{abstract}

The 2020 annual meeting started on the afternoon of October 18th, chaired by the Chairman of the Chinese Geophysical Society Prof. Chen Xiaofei, an academician of the Chinese Academy of Sciences. Academician Zheng Yongfei announced the outstanding paper awardees of the 2019 annual meeting. Academician Xu Yigang from Guangzhou Institute of Geochemistry, Chinese Academy of Sciences delivered an invited talk titled "Deep processes and habitable Earth", and Academician Gao Rui from Sun Yat-sen University delivered an invited talk titled "Deep seismic reflection profiles, dense seismic arrays, and MT jointly reveal the deep process of land-land collision in the Qinghai-Tibet Plateau". Academician Pan Yongxin from the Institute of Geology and Geophysics, Chinese Academy of Sciences, delivered an invited presentation titled "The Explorations of Mars: review and perspective". Academician Xiao Wenjiao from Xinjiang Institute of Ecology and Geography, Chinese Academy of Sciences gave an invited presentation titled "Multiple Collages and Central Asian Continent Accretion"; Academician Cui Peng from Chengdu Institute of Mountain Disasters and Environment, Chinese Academy of Sciences and Ministry of Water Resources gave an invited presentation titled "Disaster Risk of Sichuan-Tibet Railway and its Prevention and Control Research"; and Professor-level senior engineer Zhao Bangliu of China Petroleum Exploration and Production Branch gave an invited talk titled "The key role of geophysical technology in the exploration and development of shale gas in the Sichuan Basin".

On the morning of October 18th, the Chairman of the Chinese Geophysical Society Academician Chen Xiaofei presided over a forum on the frontiers of geophysics at the 36th Annual Conference of the Chinese Geophysics Society. Professor Zhang Keke from the Macau University of Science and Technology gave a report on "Macau High-precision Geomagnetic Satellite Constellation: Scientific Significance and Application Value"; Research Professor Ding Zhifeng from the Institute of Geophysics, China Earthquake Administration gave a report on "Research Progress of Seismic Array Detection of Deep Structures in Mainland China"; Jiang Liangwen, a professor-level senior engineer of the China Railway Second Academy Engineering Group Co., Ltd., made a report on
"Needs for Geophysical Exploration of Sichuan-Tibet Railway"; Professor Zhang Huai from the University of Chinese Academy of Sciences delivered a presentation on "Geodynamics in the Era of Big Data" and Research Professor Di Qingyun from the Institute of Geology and Geophysics, Chinese Academy of Sciences, gave a report on "Key Technologies and Equipment for Deep Exploration".

These conference reports, cutting-edge lectures and academic presentations in the sessions discussed topics from different professional perspectives, highlighting the very interesting tectonic structures, seismic disasters, oil and gas and mineral resource exploration, planetary evolution and livable environment, deep space/deep sea/deep ground in the field of Earth sciences, big data in geosciences, and other hot topic issues. Most of the sessions were full, with enthusiastic discussions and interactions among attendees, indicating that these new theories, new technologies, and new methods of Earth sciences have received extensive attention. Thus, basic research on frontier issues in Earth sciences meets many fundamental needs of the country.

On the afternoon of October 19th, the Chinese Geophysical Society Council Enlarged Meeting and the China Geophysical Science and Technology Award Awarding Conference were held. The meeting was chaired by Vice Chairman Xiong Shengqing. More than 260 directors, member representatives and principals from all branches and local societies attended the meeting. SecretaryGeneral Guo Jian made a report on the work of the society in 2020.

On the evening of October 19th, the editorial board meetings of "Earth and Planetary Physics (EPP)" and the "Chinese Journal of Geophysics" were held.

This academic annual meeting also conducted the selection of outstanding student papers, with a total of 184 students selected as winners from this academic conference.

In summary, the 2020 Annual Meeting of the Chinese Geoscience Union successfully held 92 sessions (including 1 international session). Many high-level scientific research results were presented at this annual meeting and some new academic perspectives were proposed. Due to the overwhelming number of achievements, new academic viewpoints, and new subject growth, notable points are given in the minutes of each symposium, following the order of scientific and technological content. For more details, please refer to the minutes of each symposium (soon to be published on the society website (http://www.cgscgs.org.cn/) and in the 2020-2021 Newsletter).

Contributed by Qinghua Huang.

Translated by Zhonghua Yao.

Accepted article online 05 JAN 2021.

C 2021 by Earth and Planetary Physics. 